Rodrigo García de la Sienra

\title{
El discurso institucional en las obras didácticas
}

Para poder abordar el tema del "discurso institucional", habrá de pensarse la institución como un organismo, como un ser vivo que encuentra sus modos de sustentación al interactuar con su medio, y que para tales fincs necesita del establecimiento de ciertos mecanismos que le permitan operar desde una posición que, por definición, le corrcsponde.

Todos los aspectos de la vida social (imaginario, cconómico, etc.), al igual que sus productos, cstán regidos por las vicisitudes de la institucionalidad. ${ }^{1}$ Esto significa que la cultura encuentra su modclado mediante un proceso de pugna en el cual lo individual, lo espontáneo y lo caótico se ven insertos en una instancia que los abarca y que les asigna un sitio con una función determinada. Dc esta manera lo individual pasa a formar parte de una grupalidad, lo espontáneo se reifica y lo caótico encuentra su lugar en una instancia ordenadora de mayor amplitud -aunque esta última pueda tener, en un momento dado, matices de desarticulación-.

Se puede decir que, dentro de esta instancia abarcadora, existe una pugna entre las diferentes instituciones por extrapolar hacia la sociedad el orden que las constituye, de manera que las

${ }^{1}$ Enticndo a las instituciones como algo que en un principio fuera originalidad, alturidad no clasificada, y que en el momento de adquirir un stetus, un lugar en cl sistcma, adquieren una unidad. una mismidad quc les otorga el entorno que las abarca. A cste movimiento se le podria llamar institucionalización. 
demás resulten insertas en un orden producido según las pautas propias de uno de los actantes, orden que se toma de esta maneга en un actante hegemónico. ${ }^{2}$

Así que se puede hablar de una jerarquización en la vida de las instituciones, lo que a su vez nos lleva a la idea de institución. Y es que hablar de una institución en general no descarta, desde luego, lá existenciáa de instituciones particulares con diferentes relaciones jerárquicas entre sí, cn las que los modos de una prevalecen sobre los de las demás. De manera que el término institución posee intrínsecamente --al menos en la acepción que le doy aquí - una connotación de mando o autoridad, el cual se habrá de ejercer principalmente sobre las instituciones que ahora se ubican en el lugar que ocupaban lo individual y lo "otro" (lo no ordenado, lo no nombrado, etc.) antes de su institucionalización.

En el caso particular de la Baja Edad Media, contexto en el que se sitúan nuestros exempla, la institución posee una fuerza muy particular, debido a la naturalización de las instituciones terrenas como representaciones (o faceta visible) de la estructura divina, que no es cognoscible sino por medio de aquéllas.

Y aqui funciona la categoría, tan ilustre, del microcosmos. Esta vieja noción fue reanimada, sin duda, a través de la Edad Media y desde el principio del Renacimiento, por una cierta tradición neoplatónica. [...] El mundo está cubierto de signos que es necesario descifrar y estos signos, que revelan semejanzas y afinidades, sólo son formas de similitud [...] No existc diferencia alguna entre estas marcas visibles que Dios ha depositado sobre la superficie de la tierra, a fin de hacernos conocer sus secretos interiores, y las palabras legibles que la Escritura o los sabios de la Antigüedad, iluminados por la luz divina, han depositado en los libros salvados por la tradición (Foucault 1996: 40).

2 Mc reficro a los "actantes" en el sentido de una fundición entre una entidad delimitada y las acciones que ésta realiza, o, en su defecto (cuando es pasivo), sus "posiciones" dentro de una esinuctura de significados. 
En este punto sería de utilidad hablar de la noción de "orden", principio según el cual las cosas quedan instituidas en su forma aparentemente más natural y de acuerdo con su propia lógica. De modo que las relaciones entre la institución y las instituciones, o entre éstas y los individuos, se fijan según un principio que parecería corresponderles de manera natural y no instituida, lo que, a mi modo de ver, es un ocultamiento del origen inmanente de la hegemonía. Ahora, no se puede explicar un orden social solamente a partir de un sometimiento por parte de un actante a otro, sino que se tiene que hablar de las condiciones que lo permiten. Estas condiciones se explican mediante la metáfora de una complejidad; de ahí la necesidad de pensar en la imagen de un organismo, pues ésta muestra que el sustento del orden está implícito en la forma en que se plantea a sí mismo.

Como parte de ese organismo que pretende ocultar la inmanencia de sus fuentes, los textos didácticos medievales - y, en particular, la colección de exempla a la que aquí me referiré específicamente: Disciplina clericalis - resultan una forma de naturalizar (universalizar) las que en realidad son formas particulares de conocer y concebir el mundo. Se podría hablar aquí de una noción que, aunque también tiene su especificidad cultural en cuanto a orientación e implicaciones conceptuales, resultaría de utilidad para este planteamiento: la Weltanschauung (cosmovision). ${ }^{3}$ Los textos medievales estarían entonces inmersos en el interior de un organismo, y serían solamente vehículos reforzadores de las estructuras que, un tanto paradójicamente, posibilitan su mismo funcionamiento. Es decir que para que las obras ejemplares de la índole de Disciplina clericalis, Calila e

${ }^{3}$ Es muy posible quc el suspicaz leclor observe, al final de este texto, que resulta un tanto curioso el hecho de que emplee un concepto que implica "la visión", pues, acorde con lo que aquí mismo sc plantca, cstc hecho no scría sino un reflejo de "las posibilidades que imponen" los ordencs cognoscitivos a las instiluciones y sus individuos, a través de sus propias herramicntas $\mathrm{c}$ infertcxlualidades. 
Dimma o Sendebar, funcionen como entidades cstructurantes de la sociedad, en sus momentos religioso, moral y cultural en general, ${ }^{4}$ y éstos se conviertan en los pilares de la institución, es necesario que haya estructuras preexistentes que lo permitan, dado que la misma literatura ejemplar, para poder scrlo, apela necesariamente a una scric de estatutos culturales (de visión de) mundo) que ya son operantes, pero que pretenden ser reforzados mediante mecanismos textuales.

Hablar de una visión del mundo implica las creencias, la memoria, el imaginario de una cultura y los productos que derivan de ellos. El imaginario de quienes reciben las narraciones cs un campo propicio para que ocurra una "naturalización", dado que las formas de conocimiento de estos receptores cstán estructuradas de la misma manera que la cultura hegemónica se propone perpetuar. Propuesta y ratificación de lo preexistente, que sin serlo no podría ser convalidado. Sin la existencia previa de la estructura propuesta, que es la misma que se pretende ratificar, no tendría caso la fabricación de cuerpos textuales tan acabados como Disciplina Clericalis.

El orden particular del que he hablado (el que impone la ins(itución medieval), así como la lógica que lo rige, se encuentran solidariamente eslabonados con la doxa de la cristiandad que en aquel entonces imperaba:

Lo que para cl pensamiento medieval da unidad al concepto de "estado" o de "orden" en todos estos casos, es la creencia de que cada uno dc estos grupos representa una institución divina, es un órgano en la arquitectura del universo, tan esencial y tan jerárquicamente respetable como los Tronos y las Dominaciones celestiales de la jerarquia angélica (Huizinga 1996: 83).

4 Hablo aquí de monentos sociales para matizar el carścter dinámico e interactivo (dialécico) de las esferas sociales. Sin embargo, la manera en la que utilizo esa acepción hegeliana no es sino a mancra de "préstamo connolativo". 
En el orden medieval la hegemonía de ciertas instituciones sobre otras reposa en la base de las crecncias y del imaginario de los "individuos funcionales"; éste se constituiría como un cimiento mucho más sólido para las estructuras institucionales que la utilización de medios de confrontación directa - como podrían ser la proscripción y la cocrción física en contra de todo aquello y aquellos que amenacen de algún modo los basamentos del orden, lo que también tenía lugar en cse contextopor parte de los actantes hegemónicos para la ratificación de su postura. Pero esto no quiere decir que no existiera un movimiento de fuerzas discordante, al menos en apariencia, con este proyecto. A partir de lo anterior tienen lugar las obras didácticas, cuyo propósito es el de disuadir de un comportamiento dado - que es observable, y entonces condenable, si y sólo si es también preexistente en la sociedad- que podría resultar amenazador de los basamentos del orden social, y hacer tender a los receptores hacia otra conducta.

La naturaleza de los textos ejemplares debe ser acorde con los principios epistemológicos propios del sistema dogmático en el que son, en el claro caso de Disciplina Clericalis, insertados, adaptados - no engendrados, pues recordemos que estos textos son, en su mayoría, de un origen distinto a cste contexto-, por lo cual en este análisis haré mención de algunos principios epistémico-perceptivos surgidos a partir dc la síntesis que representa la tradición filosófica griega, al ser acoplada al contexto medieval.

Ésta fue una época impregnada por la escolástica, la cual encuentra su fundamento de manera importante en la interpretación de la filosofía de Platón y, a partir del siglo xin, de la de Aristóteles. Las implicaciones de lo anterior en relación con Disciplina Clericalis, redactada por Pedro Alfonso en el siglo XII, son más amplias que una simple cuestión temática o de presencia dc una perspectiva preceptual favorecida - como cn su momento mostraremos que existe en el texto-, pues hay un 
trasfondo sobre el cual la cuestión temática puede cobrar un sentido que ayude a interpretar aspectos particulares del desarrollo de las narraciones y sus mecanismos internos; por ejemplo, la posibilidad de extraer de los textos una relación entre comicidad y misoginia, dada en el desarrollo de éstos.

Pero mi intención no es mostrar cuál es la forma retórica mediante la cual el fenómeno cómico tiene lugar en los textos, ni la de deducir las causas sociales de la misoginia de la que éstos dan cuenta; mi intención es, más bien, esbozar un vínculo entre estos fenómenos (comicidad y misoginia) y el proyccto de una cultura en la que la razón resulta un instrumento para la naturalización de la propuesta de un orden institucional hegemónico.

Una parte significativa de la temática presente en dichos textos ejemplares está centrada en los momentos en los que sc presenta algún engaño a la razón gracias a la falibilidad de sus vías inmediatas de información: los sentidos. Éstos son destacados como parte importante de los relatos, pero siempre en subordinación a la búsqueda de un "conocimiento". Dicho conocimiento parece esbozar una dicotomía en la que se opone lo "sensible" a lo "inteligible", en la que sólo lo segundo proporciona la verdadera y efectiva forma de conocer, mientras que lo primero es un vehículo imperfecto, mediante el cual la razón es susceptible de ser engañada.

Podría sugcrirse quc la intención racionalizante y moralizadora del discurso ejemplar (propia del orden de la cultura hegemónica) coexiste con las fuerzas integradoras del pensamiento que expresa el pueblo cn el carnaval, pero manifestándose, obviamente, en sentido opuesto al de éste. Pero el que plantee esta oposición entre la institución hegemónica y otra antagónica, como por ejemplo la "carnavalesca", es por la necesidad teórica de mi planteamiento, para el que la cultura en cuyo seno surgen cstos libros ejemplares está conformada por diversos actantes que se oponen entre sí. ${ }^{5} \mathrm{De}$ modo que nuestra

${ }^{5}$ Emplco el ejemplo de lo "carnavalesco" precisamente porque resulta intere- 
división requicre ser matizada, sobre todo porque este planteamiento, a la vez que separa, concibe un organismo total, cuyas partes son instrumentos para que éste manificste su orden totalizador y abarcante.

Así como se puede considcrar la institución y las instituciones particulares como "individuos funcionales", se puede pensar en la existencia de diferentes "órdenes culturales" dentro de otro que los comprende. La concepción del mundo de la Iglesia es en este caso el orden cultural hegemónico, al que se oponc el orden del carnaval con el que cocxiste. Mediante esta oposición pretendo mostrar los ordenes coexistentes como actantes en un sistema que los abarca. Con esto se hace manifiesto el lugar de la institución: a ésta se le ubica en un espacio abstracto, vacío, que el orden particular de la Iglesia viene a llenar. Los textos como Disciplina resultan entonces producto de una episteme más global, a la vez que recurso de uno de los actantes (la Iglesia) dirigido a los individuos (como parte de una institución marginal), quicnes cncaman en sí mismos ("cn sus mentes y en sus corazones", por decirlo de algún modo) la coexistencia de las tendencias culturales antes mencionadas.

Así, existía un orden que se manifestaba en los diferentes aspectos de ese mundo, ya sea el social, el filosófico-lingúístico, o incluso el literario. La distinción, la fijación y la jerarquización ${ }^{6}$ parecían ser los productos naturales del orden, que se

sante pensar que esta forma de "subversión" cstaba, como lo ha observado en las huellas de la cultura medieval Bajtin, bastante codificada, lo que nos hace pensar en un alto grado de inslitucionalizacion. Esta institucionalización habla precisamente de una de las formas a través de las cuales la institución ganaba terreno frente a lo que en un principio fuera peligroso: Ia inteligibilización del caos y su ordenamiento a Iravés de su permisión c inserción en el organismo social, con su consiguiente funcionalización como unidad diferenciada dentro del orden imperante.

${ }^{6}$ Estas tres nociones (distinción, fijación, jerarquización) están intimamente rclacionadas entre sl. Las tres encuentran su fundamento en la identidad de las cosas, principio muy importante en la tadición occidental, pero sobre todo para cl cristianismo, para el cual el ticmpo, por ejemplo, es necesariamenie lineal, y. 
constituía de esa manera en un proyecto en movimiento; de ahí que en el terreno de la filosofía del lenguajc aparecieran con fuerza las tentativas de algunos filósofos de establecer una lengua, como la llamaría Eco, "perfecta", con un carácter universal; proyecto que, curiosamente, tenía por objcto la conversión de los infieles (su inserción como individuos en el orden). Tal sería el caso de Ramón Lull y su Ars Magna. ${ }^{3}$

En el otro extremo de la oposición tendríamos el principio "pagano", encarnado en la cultura grotesca:

A diferencia de la fiesta oficial, el carnaval era el triunfo de una especie de liberación transitoria, más allá de la órbita de la concepción dominante, la abolición provisional de las relaciones jerárquicas, privilegios, reglas y tabúes. Se oponía a toda perpetuación, a todo perfeccionamiento y reglamentación, apuntaba a un porvenir aún incomplcto. [...] En las fiestas oficiales las distinciones jerárquicas se destacaban a propósito. cada personaje se presentaba con las insignias de sus títulos, grados y funciones y ocupaba un lugar reservado a su rango. Esta fiesta tenía por finalidad la consagración de la desigualdad... (Bajtín 1987: 15).

...y de la distinción entre las identidades, para que el orden (en el que cada cosa distinta ocupa su lugar) tuvicra como parte constitutiva la jerarquización de dichas identidades diferencia-

por lo tanto, único. perfectamente diferenciado. As1, como cada cosa es idéntica a si misma y ocupa un único lugar en el ticmpo y en el espacio, cs imposible que se piense en el cosmos (orden) como algo que tiende a la indiferenciación. a lo cícli$\mathrm{co}$, en donde la regeneración de lo icricno es promesa de vida que diluye la responsabilidad cristiana de la vida única. en función de la cual se tendrá otra igualmente irrepctible. Esta concepcion de lo distinto delienc el movimiento de la historia, fijando los sucesos y la cxistencia en la linea de lo inccuperable. Gracias a esto vienc la jerarquización, quc consiste en el establecimicnto y fijación de un orden parlicular de cosas, en el que lo principal es destacar sus distinciones.

' Si la lengua cra un constituyente definitivo de la otredad de los infieles. ¿no serla este csíucrzo filosófico de elaborar un sistema lingústico universal, un inrento por funcionalizar a los otros dentro de un proyecto en el que perderian su mismidad. que para los fieles es otredad? 
das, y de ese modo, los privilcgios propios de la jerarquía sc sustentaran sobre cl orden mismo, sobre la naturaleza aparentc de las cosas. La literatura ejemplar es, pucs, una mucstra de los procesos que cste orden jerarquizado requería para constituir y refrendar sus capacidades de supervivencia como organismo. La cultura popular podría ser una muestra de cómo las partes hegemónicas fundamentan su fuerza mediante el ejercicio de ciertos mecanismos de oposición (o subrepticia integración) a sus contrarios, implantando la propia concepción del mundo sobre el terreno de las manifestaciones culturales. Si la cultura del carnaval en un momento dado puede ser identificada con lo corporal, con lo fértil y lo orgánico - fucrzas a las que Lcgendre (1979), siguiendo a Freud, quizás llamaría "libidinales" - tchomos por el otro lado la cultura del exilio de los sentidos frente a la vida de lo intcligible, para la cual el cuerpo, sus apetitos y sus productos resultan no sólo desdeñables, sino peligrosos y combatibles.

La materia de las narraciones ejemplares a las que me rcficro cs, pues, más comprensible a partir de la existencia de un marco según el cual existe una oposición cntrc las formas de expresión del orden cultural hegemúnico y las de aquellas instituciones que opcran como marginales o como fuerzas potencialmente disgregadoras de la postura propucsta por la institución dominante. Por eso es que las namaciones no manifestarán la presencia de figuras simbólicas que encamen los valores positivos del cuerpo o de los sentidos; por el contrario, encontraremos acaso que la presencia de algún elemento de dicho universo estará cxclusivamente en la parte dc la mostración negativa con la que los exempla trabajan.

Platón distinguía con nitidez entre los sentidos "superiores" de la visión y la audición y los sentidos "inferiores" del olfato, el gusto y el tacto, y destacaba sólo a los primeros como vías hacia el conocimiento racional: "Dios ideó el don de la vista para 
nosorros de modo que podamos observar los movimientos que han sido descritos por la razón en los cielos, y aplicarlos a las nociones de nuestra propia mente. [...] Y lo mismo vale para la voz y la audición". Se había percatado de que la visión y la audición también podían, como los otros sentidos, excitar lo que él llamaba un "placer irracional" en el nivel de la mera sensáción. Pero dejarse gobernar por las sensaciones era algo que debia resultar moralmente repugnante a las personas virtuosas y de buen gusto (Humphrey 1995: 68-69).

En Disciplina Clericalis tenemos varios ejemplos de esta jerarquización de la "razón" frente a los sentidos, que son instrumentos suyos, pero poco confiables, dada su susceptibilidad frente a los engaños de las portadoras del mundo de los placeres scnsuales, que son las mujeres:

Succdió, sin embargo, que el dueño se hirió un ojo con una rama y volvió a casá antes de lo calculado y sin ver nada con el ojo hcrido y. llegando a la entrada de su casa, llamó a la puerta. La mujer, comprendiendo lo que pasaba, escondió muy turbada al amigo quc había llamado y corrió después a abrir la puerta a su marido [...] Temió la mujer que, si entraba cn la habitación, viera al amigo escondido [...] "Permite —dijo ella—, queridisimo esposo, quc tc fortalczca el ojo sano con artes médicas y fórmulas de encantamiento, no vaya a pasar con cl lo que ya me pasó con el ojo herido, ya que tu daño es mi daño". Y poniendo su boca sobre el ojo sano, lo cstuvo cubriendo hasıa que cl amigo escondido pudo salir sin que el marido se diera cuenta (M. J. Lacarra, ed. 1980: 60).

El entendimiento no es capaz, ni siquiera a través de su heramienta perceptiva más clcvada, de dar cuenta del engaño de la transgresora del orden moral propuesto por la cultura hcgemúnica. Pero en este exemplum la trampa no es tan grave, puesto que el sentido de la vista está obnubilado. Veamos, más adelantc, el Ejemplo de la espada: 
...uno, teniendo que salir de viaje, confró su mujer a su suegra para que se la cuidara. Pero la mujer amaba en secreto a un joven y se lo dijo a su madre. Ésta consintió en el amor y, preparando un festín, llamó al amigo. Mientras estaban comiendo, llegó cl marido y llamó a la puerta. Se levantó la mujer para hacer enirar al marido, quedándose la madre con el amante de su hija, sin saber qué hacer, ya que no había sitio para esconderlo. [... cogió la artera vicja una espada desenvainada y sc la entregó al joven, y le mandó que al entrar el marido de su hija estuviera así ante la puerta [...]. Y cuando, abierta la puerta, lo vio el marido allí parado [...]: "¿Qué es esto - dijo-, mi querida dueña?". Entonces la mujer: “Hijo mío, vinieron aquí tres hombres persiguiendo a ćste y nosotras, abricndo la puerta, le dejamos entrar con la espada, hasta que se fueran los que querían matarlo [...]". Y dice el marido: "Dios te bendiga, dueña, que asi has librado a éste de la muerte". Y entrando, llamó al amante de su mujer y le invitó a sentarse a su lado. Y después de tranquilizarlo con suaves palabras, lo retuvo con él hasta el anochecer (Lacarra: 61-62).

En este caso nos enfrentamos a un engaño que tienc lugar, no a partir de la disminución de los sentidos, sino de la interpretación errónea de un estímulo y una circunstancia; ahí es mucho más clara la falibilidad de los sentidos. Es importante señalar que siempre, como premisa importante del argumento implícito en estos textos sobre engaños de la mujer al hombre, tencmos que el hombre engatusado jamás es alguien que se deje llevar por los sentidos en cuanto al placer que ćstos proporcionan. Esto es interesante, puesto que la ridiculización que sufre, dadas las circunstancias en que se le toma el pelo, lo hace a la vez virtuoso y débil; expuesto, ingenuo como cordero que camina al matadero. Esto nos hace pensar no en una posible inmoralidad castigada del hombre cngañado, sino cn otras dos cosas: cn lá virtud propia de la ingenuidad (que hace al hombre "como niño" o como "oveja") y en los resultados nefastos de no estar atentos contra los sentidos y contra quienes encaman el domi- 
nio de las fuerzas de este mundo, de lo irracional, de lo fértil; dominio que ha sido asociado con una

larga tradición del lado oscuro de la mujer, de la deidad que simboliza el principio femenino, la Luna, y que es una fuerza fertilizadora [...] el poder creador y destructor [...] lo misterioso, lo oscuro, lo inasible, lo desconocido (Cándano 1995: 368-369).

Estos principios, que definitivamente son paganos, están en el lado de la cultura marginal, de la cual la mujer se hace depositaria gracias a la cjemplificación de que es objeto. Lo que resulta interesante con relación al hombre -quien es el destinatario de la enseñanza - es si cl hecho de su ridiculización (fenómeno social) cs producto de una interiorización previa de los principios ahí propuestos y un simple reforzamiento, o si es presentado como una consecuencia natural y fáctica, que ha de convencer de algo de lo que no se estaba previamente convencido, 0 al monos no totalmente. En cualquiera de los dos casos, la risa de los dcmás es un factor dc presión no deseable, un "castigo de las costumbres" (Bergson 1973: 25) que funciona valorativamente en contra de los sentidos y, por ende, de cualquier cultura que los integre con un valor positivo. Así que la risa social, escarnecedora, ocasiona que el razonamiento natural induzca a concluir dos cosas: a) que el dejarse llevar por los sentidos no es bueno, y b) que por lo mismo, todo aquello que promueva los sentidos como valor va en contra de la razón o del ingenio humano; capacidad que fuc, en palabras del mismo Pedro Alfonso,

destinada, por precepto del Creador, a dedicarse, mientras permanezca en el mundo, a la búsqueda y ejcrcicio de la santa filosofía [¿qué hay más racional que la filosofía?], por medio de la cual logre un mejor y mayor conocimiento de su propio Creador y aprenda a vivir en moderada continencia. así como 
a precaverse de los peligros que le amenazan [como ser objeto de la risa social] y a caminar en estc mundo por una senda que lo lleve al reino de los cielos (Lacarra: 43).

Vemos aquí que el ingenio por sí solo no es bueno, y que las mujeres, en la mayoría de los casos, lo utilizan para cngañar y, sobre todo, para poder llevar a cabo sus actos "incontinentes" -mediante los cuales, desde lucgo, hacen tropezar al hombre-. Existe, pues, una expiación de la culpabilidad de éste, atribuida a la mujer (que gobierna los sentidos, puesto que posee gran ingenio) de mancra indirecta, pcro notable.

Pero a pesar de que exista la posibilidad del mal empleo del caletre (para ganarse el mundo y el gobierno del placer de los sentidos, como lo hacen las malas mujeres), se observa en cstos textos que el conocimiento (sólo alcanzable por la razón) goza de un privilegio como vía para cl ascenso cclestial, que sc sustenta sobre la oposición entre lo sensible y lo inteligible, o entre lo terreno y lo celeste, o lo corporal y lo espiritual, etc. Es pues esta concepción la que da pic a la propuesta cstigmatizante dc los sentidos, que a su ve\% resulta ser, en última instancia, el principio selector de la materia de estas naraciones ejemplares.

En un mundo donde la cúpula del poder político pretendía establecer un orden social - y un sólido dominio sobrc $\mathrm{cl} \mathrm{hom-}$ bre-mediante la sumisión absoluta a los principios morales y religiosos emanados de la hegemónica Iglesia, una de las facetas subliminales del discurso institucional era la denostación del hedonismo, particularmente del sexual y cirenaico. Se buscaba crear concicncia respecto de que la buena conducta moral individual era sinónimo de lealtad a Dios, los señores y el pater familiae.

Para abonar esta parcela de sus imperativos fines, la autoridad de turno debía alertar al varón en lo concemiente a la ha- 
bilidad de la mujer para engañarlo y para crear las apariencias pertinentes a sus lúbricos objetivos; debía advertirlo acerca de la inteligencia femenina, intuitiva y oportunista, destructora del saber ancestral del hombre. Y qué mejor extrapolación del orden anhelado que ilustrar con profusos, sencillos, generalizables, persuasivos y difundidos relatos breves la fuente principal de la risa que escarnece, que se burla dcl otro: ¡ la que se ganan los timoratos que "prestan oídos", que hacen caso, de la palabra de la mujer! Ése fue uno de los campos donde mayor efectividad tuvieron las colecciones de exempla -diseminadas por los predicadores, representantes de las entidades celestiales y terrenas del orbe-, las que sin duda constituyeron herramienlas fundamentales para la sustentación de la institución medieval más importante: la conformada por la alcumia de la dicotomia masculina oratores-bellatores.

\section{Bibliografia}

Baurín, Mijail, 1987. La cultura popular en la Edad Media y el Renacimiento (Madrid: Alianza Universidad).

Bergson, Henri, 1973. La risa: ensayo sobre la significación de lo cómico (Madrid: Espasa-Calpe).

Beristain, Helena, 1985. Diccionario de retórica y poética (México: Porrúa).

Beuchor, Mauricio, 1991. La filosofía del lenguaje en la Edad Media (México: UNAM).

Candano, Graciela, 1995. "Enxemplo del omne e de la muger e del papagayo e de su moça", en Palabra e imagen en la Edad Media (México: UNAM).

DerridA, Jacques, 1989. La escritura y la diferencia (Barcelona: Anthropos).

Eco, Humberto, 1993. La búsqueda de la lengua perfecta (Barcelona: Grijalbo-Mondadori).

Fouscault, MicheI, 1996. Las palabras y las cosas (México: Siglo XXI). 
GonzÁlez, César, 1995. A lo invisible por lo visible: imágenes del occidente medieval (México: UNAM).

Huizinga, Johan, 1996. El otoño de la Edad Media (Madrid: Alianza Universidad).

Humphrey, Nicholas, 1995. Una historia de la mente: la evolución y el nacimiento de la conciencia (Barcclona: Gedisa).

LACARRA, María Jesús, ed., 1980. Disciplina Clericalis (Zaragoza: Guara Editorial).

Legrndre, Pierre, 1979. El amor del censor (Barcelona: Anagrama). Martinez de la Escalfra, Ana María, el al., 1996. Retóricas verbales y no verbales (México: UNAM).

PANOFSKY, Erwin, 1986. Arquitectura gótica y pensamiento escolástico (Madrid: La Piqueta).

RoßIN, Regine, 1993: "Para una sociopoética del imaginario social", en François Pcrús, ed., 1994: Historia y literatura (México: Instituto de Investigaciones José María Luis Mora).

Romero, José Luis, 1941. La Edad Media (México: FCE). 